\title{
Prevalence of Dietary Supplements Use among Gymnasium Users
}

\author{
Ayman H. Jawadi, ${ }^{1}$ Abdulmalik M. Addar, ${ }^{2}$ Abdulaziz S. Alazzam, ${ }^{2}$ \\ Fahad O. Alrabieah, ${ }^{2}$ Abdullah S. Al Alsheikh, ${ }^{2}$ Roaa R. Amer, ${ }^{2}$ Al Anoud S. Aldrees, ${ }^{2}$ \\ Maha A. Al Turki, ${ }^{1}$ Ali K. Osman, ${ }^{1}$ and Motasim Badri ${ }^{3}$ \\ ${ }^{1}$ College of Applied Medical Sciences, KSAU-HS, Riyadh, Saudi Arabia \\ ${ }^{2}$ College of Medicine, KSAU-HS, Riyadh, Saudi Arabia \\ ${ }^{3}$ College of Public Health and Health Information, KSAU-HS, Riyadh, Saudi Arabia
}

Correspondence should be addressed to Ayman H. Jawadi; dr.jawadi@gmail.com

Received 16 November 2016; Revised 24 February 2017; Accepted 21 March 2017; Published 5 April 2017

Academic Editor: J. B. German

Copyright (C) 2017 Ayman H. Jawadi et al. This is an open access article distributed under the Creative Commons Attribution License, which permits unrestricted use, distribution, and reproduction in any medium, provided the original work is properly cited.

Background. Several studies showed that regular gymnasium users use various dietary supplements without comprehension of their potential risks. Objective. To determine the prevalence and dietary supplement intake and assess the awareness of supplement use among regular gymnasium users in Riyadh, Saudi Arabia. Methods. A descriptive cross-sectional study was conducted among regular gymnasium users in Riyadh, Saudi Arabia, between April 2015 and June 2015. A validated structured questionnaire was used. Results. The study included 299 participants. Of these 113 (37.8\%) were dietary supplements users and this was more common among males than females (44.7\% versus $16.4 \%)$. Gender based analysis showed that males were exercising more frequently than females and the type of cardiovascular exercise was more among them. The most commonly used supplements were whey protein (22.1\%), amino acids (16.8\%), multivitamins (16.8\%), creatine (11.5\%), and omega $3(11.5 \%)$. The reasons for taking dietary supplements were to improve body shape (47.7\%), increase health (44.2\%), and improve performance (41.5\%). Conclusion. Most of the information about supplements was obtained from unreliable sources. More studies are needed to better understand supplements use and their impact on health in Saudi Arabia.

\section{Introduction}

The Kingdom of Saudi Arabia has an expanding population in which the young constitute the majority, with an increasing number of people attending athletic activities and easy access to dietary supplements [1]. The Dietary Supplement Health and Education Act defines dietary supplements as "any product (other than tobacco) intended to supplement the diet that contains one or more dietary ingredients." They embrace diet fortifying nutritional elements such as herbs, vitamins, meal supplements, and nutritional athletic merchandise midst others [2-4]. According to the United States of America Food and Drug Administration (FDA) any product labeled as a "supplement" means that its contents and the claims on the label have not been approved or evaluated by the FDA [5, 6]. It is well documented that the use of some of these products may lead to serious health injury [7]. The regular gymnasium users are at risk resulting from taking various categories of nutritional supplements intended for athletic improvement [8].

Popularity of these supplements along with their easy access makes us question their consumption among regular gymnasium users, who engage in sports for pleasure and not monetary gain or professional benefits, in Saudi Arabia. There was only one research discussing supplement use among professional athletic football players in Saudi Arabia that included 105 athletes of whom $93.3 \%$ were using dietary supplements, that is, sports drinks $88.7 \%$, vitamin C $82.6 \%$, multivitamins $52 \%$, omega $618.6 \%$, creatine $16.3 \%$, and Ginkgo biloba $10.2 \%$. The majority of participants reported improvement of health and performance as the main reason 
for using dietary supplements [2]. However, there is no data addressing this issue in nonprofessional athlete in Saudi Arabia. In Beirut, Lebanon, $36.3 \%$ of gymnasium users were reported to use supplements [9]. Dietary supplements are used for different intentions such as building muscles, better health, and improving performance. Some studies have shown that people have different opinions about the use of dietary supplements [10]. Supplement users have different sources of information about the supplements they are taking. Studies from Lebanon and Iran reported that coaches are the main source of information about dietary supplements among users $[9,11]$.

This research is carried out to shed light on nonprofessional use of dietary supplements among both genders in Saudi Arabia. Since there is no data available regarding this issue of the regular gym exercises supplement use, it is crucial to address this important topic.

\section{Methods}

A descriptive cross-sectional study was conducted in the city of Riyadh, Saudi Arabia, from April 2015 to June 2015. A pilot study was conducted and showed that $17 / 51=33.3 \%$ of the respondents were using supplements. Therefore, at $80 \%$ power and 95\% confidence level, the required sample size was calculated to be 342 350 participants. However, due to the difficulty of participant recruitment only 299 participants' responses were collected. This is mainly due to difficulty faced in getting consent of female health centers. Culturally it is not acceptable to disturb or break trainer's confidentiality. Thus, the major health centers in Riyadh were identified and those ones who were willing to participate in the study were visited. The sampling technique used was purposive sampling. Subjects interviewed had to be gymnasium users, who engage in sports for pleasure and not monetary gain or professional benefits. Both males and females aged between 18 and 45 years being in Riyadh at the time of the study were included. Professional athletes (a person who takes sports as their main monetary gain), coaches, abusive drug users, and participants below 18 years of age or over 45 years were all excluded. All participants signed a formal consent after being informed about the objectives of the study. The Ethics Committee of King Abdullah International Medical Research Centre approved the study.

An individual interview questionnaire which was previously tested in a pilot study and final version was used to collect information about demographic and socioeconomic data, lifestyle, type of supplements, measuring blood pressure, frequency, sources of information, and beliefs regarding supplements use. Finally, anthropometric parameters weight $(\mathrm{Kg})$ and heights $(\mathrm{Cm})$ were taken and then Body Mass Index (BMI) was calculated to assess physical status. Anthropometric measurements and demographic data were collected to explore the possibility of association between the consumption of dietary supplements and these parameters. All questions and measurements were taken by the researchers themselves. Blood pressure measurement was done using a British hypertension society certified blood pressure machine, Omron M7 (HEM-780-E). Weight and height were measured using equipment available at the visited health clubs.

Data were summarized medians (IQR) or proportions and compared using the Mann-Whitney or $\chi^{2}$ square test. Statistical analysis was conducted using the Statistical Package for Social Studies software (IBM SPSS version 19; USA). All tests were two-sided and a $P$ value $<0.05$ was considered significant.

\section{Results}

The study included 299 participants. The prevalence of dietary supplements use among the gymnasium users was $113 / 299$ (37.8\%). Table 1 shows the demographic characteristics of supplement users and nonusers. Age did not differ between the two comparison groups $(P=0.133)$. Gender distribution was significantly different in the two groups $(P<0.0001)$ with males amounting to $89.4 \%$ of dietary supplements users and $67.2 \%$ of nonusers, and female dietary supplements users and nonusers constituted $10.6 \%$ and $32.8 \%$ of study participants, respectively. Saudi nationals predominate among study participants; $82.3 \%$ and $78.8 \%$ of dietary supplements users and nonusers were Saudis. However no significant difference was observed between the two groups in terms of nationality $(P=0.187)$. Smoking status differed significantly between the two groups $(P=0.005)$; smokers amounted to $45.1 \%$ of dietary supplements users versus $29 \%$ of non-supplements users. Level of education was not significantly different between the two groups $(P=0.945)$. Those with bachelor degree were the group with highest frequency among both dietary supplements users (54.9\%) and nonusers $(58.1 \%)$ compared with participants with other levels of education.

Level of income was approximately similar in the two groups $(P=0.157)$. The highest percentage of participants among dietary supplements users and nonusers was those with lowest income: $34.5 \%$ and $31.2 \%$ with income within $3,000<5,000$ SR $(1$ USD $=3.75$ SR), followed by $29.2 \%$ and $28.5 \%$ with income within $10,000<20,000 \mathrm{SR}$, respectively.

Gender based analysis was done and showed that males were exercising more frequently than females and for a longer period. No difference was found in smoking status, type of supplements, sources of information, type of exercise, and beliefs between male and female participants.

The most used supplements users acquired information mainly from online sources (38\%) followed by advice from coach $(35.4 \%)$, by physician (13.3\%), academic journals (12.4\%), dietician (11.5\%), and magazines (3.5\%) (Table 2). No statistically significant difference was found between male and female gymnasium users for source of information about supplement use.

Height (in meter) among the supplement users and nonusers was 1.73 and 1.70 while their weight $(\mathrm{kg})$ was 74.6 and 79 , respectively (Table 3 ). The BMI among supplement users and nonusers was 24.8 and 27.6, respectively, indicating that the non-supplement users were overweight as compared with the users and the difference was statistically significantly 
TABLE 1: Demographic characteristics of participants.

\begin{tabular}{|c|c|c|c|}
\hline Characteristic & Supplements users $n(\%)$ & Non-supplements user $n(\%)$ & $P$ value \\
\hline Age (years), median (IQR) & $27(22-31)$ & $28(23-33)$ & 0.133 \\
\hline \multicolumn{4}{|l|}{ Sex } \\
\hline (i) Male & $101(89.4)$ & $125(67.2)$ & \multirow{2}{*}{$<0.0001$} \\
\hline (ii) Female & $12(10.6)$ & $61(32.8)$ & \\
\hline \multicolumn{4}{|l|}{ Smoking status } \\
\hline (i) Yes & $51(45.1)$ & $54(29)$ & \multirow{2}{*}{0.005} \\
\hline (ii) No & $62(54.9)$ & $132(71)$ & \\
\hline \multicolumn{4}{|l|}{ Nationality } \\
\hline (i) Saudi & $93(82.3)$ & $141(78.8)$ & \multirow{2}{*}{0.187} \\
\hline (ii) Non-Saudi & $20(17.7)$ & $45(24.2)$ & \\
\hline \multicolumn{4}{|l|}{ Level of education } \\
\hline (i) Less than high school & $1(0.9)$ & $2(1.1)$ & \multirow{4}{*}{0.945} \\
\hline (ii) High school & $35(31)$ & $52(28)$ & \\
\hline (iii) Bachelor & $62(54.9)$ & $108(58.1)$ & \\
\hline (iv) Master/Ph.D. & $15(13.3)$ & $24(12.9)$ & \\
\hline \multicolumn{4}{|l|}{ Income (SR) } \\
\hline (i) 3,000 to $<5,000$ & $39(34.5)$ & $58(31.2)$ & \multirow{5}{*}{0.157} \\
\hline (ii) 5,000 to $<10,000$ & $29(25.7)$ & $35(18.8)$ & \\
\hline (iii) 10,000 to $<20,000$ & $33(29.2)$ & $53(28.5)$ & \\
\hline (iv) 20,000 to $<30,000$ & $8(7.1)$ & $25(13.4)$ & \\
\hline$(\mathrm{v})>30,000$ & $4(3.5)$ & $15(8.1)$ & \\
\hline
\end{tabular}

$P$ value: Mann-Whitney for difference in medians and $\chi^{2}$ test for difference proportions.

TABLE 2: Source of information

\begin{tabular}{lcccc}
\hline Source of information & $n(\%)$ & Males (\%) & Females (\%) & $P$ value \\
\hline Online & $43(38)$ & $34(15)$ & $9(12.3)$ & $11(15.1)$ \\
Coach & $40(35.4)$ & $29(12.8)$ & $5(6.8)$ & 0.565 \\
Physician & $15(13.3)$ & $10(4.4)$ & $2(2.7)$ & 0.626 \\
Academic journals & $14(12.4)$ & $12(5.3)$ & $2(2.7)$ & 0.409 \\
Dietician & $13(11.5)$ & $11(4.9)$ & $0(0)$ & 0.366 \\
Magazines & $4(3.5)$ & $4(1.8)$ & & 0.252 \\
\hline
\end{tabular}

$P$ value: $\chi^{2}$ test.

TABLE 3: Anthropometric measurement and blood pressure.

\begin{tabular}{|c|c|c|c|c|c|c|}
\hline Characteristic & Supplements users & Non-supplements user & $P$ value & Males & Females & $P$ value \\
\hline Height (meters), median (IQR) & $1.73(1.67-1.76)$ & $1.70(1.64-1.76)$ & 0.021 & $1.73(1.69-1.77)$ & $1.64(1.59-1.68)$ & 0.000 \\
\hline Weight (KGs), median (IQR) & $74.6(68-82.8)$ & $79(69.4-89.3)$ & 0.010 & $79.5(71.5-89.2)$ & $68(62-77.5)$ & 0.000 \\
\hline Body Mass Index, median (IQR) & $24.8(23.3-27.5)$ & $27.6(24.7-30.3)$ & $<0.0001$ & $26.4(24.2-29.7)$ & $26(22.8-28.5)$ & 0.050 \\
\hline Diastolic, median (IQR) & $72(65.5-79)$ & $77(70-85)$ & $<0.0001$ & $74(67-80)$ & $80(70-89)$ & 0.000 \\
\hline Systolic, median (IQR) & $119(111-128)$ & $121(113-128)$ & 0.283 & $121(113-128)$ & $120(110-128)$ & 0.073 \\
\hline
\end{tabular}

$P$ value: $\chi^{2}$ test.

$(P<0.0001)$. This observation could be due to the fact that supplement users were exercising for a longer time ( $<10$ years) than nonusers (Table 4).

The diastolic blood pressure median was significantly higher $(P<0.0001)$ among the non-supplement users as compared with the users ( 72 versus $77 \mathrm{mmHg}$ ). Although this difference was statistically significant it is within normal range. The systolic blood pressure among the two groups was
119 versus 121, respectively, but the difference was not statistically different. Differences between males and females are also shown. Compared with females, males were significantly taller $(P<0.0001)$, were more obese $(P<0.0001)$, and had lower median diastolic blood pressure $(P<0.0001)$ (Table 3$)$.

Duration of exercise for less than one year was highest among nonusers of supplements (61.8\% versus $26.5 \%)$ and males were exercising for a longer time than females 


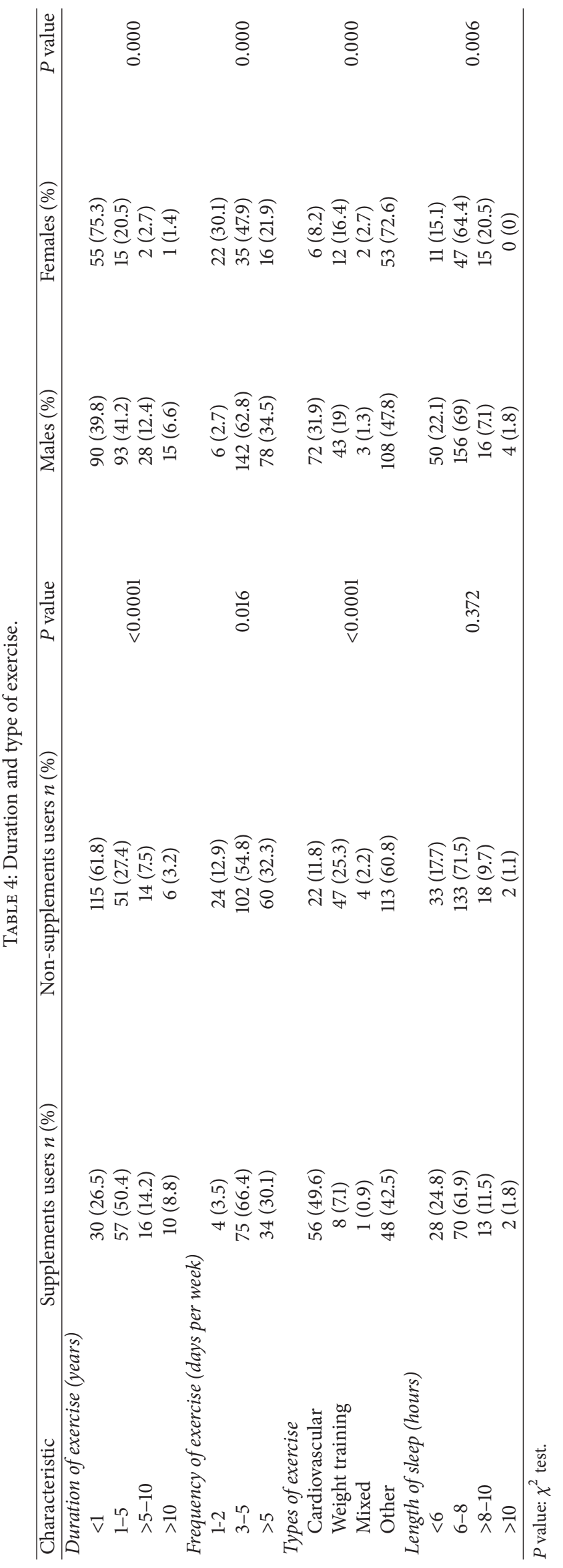


TABLE 5: Reasons for supplement use.

\begin{tabular}{|c|c|c|c|c|}
\hline Reason of supplement use & Males (\%) & Females (\%) & $N(\%)$ & $P$ value \\
\hline Appearance & $42(18.6)$ & $12(16.4)$ & $54(47.7)$ & 0.679 \\
\hline Improve health & $36(15.9)$ & $14(19.2)$ & $50(44.2)$ & 0.518 \\
\hline Improve performance & $38(16.8)$ & $9(12.3)$ & $47(41.5)$ & 0.360 \\
\hline Lose weight & $10(4.4)$ & $3(4.1)$ & $13(11.5)$ & 0.909 \\
\hline Prevent injury & $5(2.2)$ & $5(6.8)$ & $10(8.8)$ & 0.055 \\
\hline Recovery & $3(1.3)$ & $4(5.5)$ & $7(6.1)$ & 0.041 \\
\hline
\end{tabular}

$P$ value: $\chi^{2}$ test.

$(P<0.000)$ (Table 4$)$. The frequency of exercise was highest among those who exercise 3-5 days per week and was higher among supplement users than nonusers (66.4\% versus $54.8 \%$ ). Approximately $50 \%$ versus $12 \%$ of the supplement users and nonusers do cardiovascular exercise and males were exercising more frequently than females, which was statistically significant $(P<0.000)$.

In terms of type of exercise, supplement users were mainly practicing cardiovascular training while nonusers were doing other types of exercise more frequently (49.6\% versus 60.8 ; $P<0.0001)$. Female gymnasium users were practicing into other types of exercise than males $(72.6 \%$ versus $47.8 \%)(P<$ $0.000)$. Length of sleep did not differ significantly between the two groups $(P<0.372)$. However, males were getting less sleep than females $(P<0.006)$. The major reported reasons for supplements use were for appearance $(47.7 \%)$ and to improve health (44.2\%) and performance (41.5\%) (Table 5). Others were to lose weight (11.5\%), to prevent injury $(8.8 \%)$, and for recovery (6.1\%). No statistically significant difference was found between male and female gymnasium users for the reason of using supplements.

The most common belief among all participants was that supplements increase the amount of training that the participant can undergo, followed by the belief that supplements provide more energy and make the participants healthier (Table 6).

\section{Discussion}

Supplements are increasing in use in Saudi Arabia and becoming easier to acquire. They are tempting to use to get better exercise outcomes. With the potential harm these supplements may have, it is important to address their availability among regular gymnasium users. No difference was found between genders in smoking status, type of supplements, sources of information, type of exercise, and beliefs and for this reason comparisons were not made between male and female supplements users. A study conducted in Finland Olympic athletes concluded that of $81 \%$ of those who use nutritional supplements only $27 \%$ of them had the opportunity to consult a dietary specialist before using them [12]. Another study done in the United States showed that $89 \%$ of adult athletes were using at least one supplement at the time of the study [13]. A study conducted in New York in 2004 found the prevalence of supplements to be $84.7 \%$ among male athletes [14]. Another study conducted in Lebanon in 2012 reported that the prevalence of supplements use was at $36.3 \%$ among exercisers in Beirut, Lebanon, gyms [9]. Supplements use among regular gymnasium users in Saudi Arabia was not sufficiently investigated. There was only one study in Saudi Arabia that has investigated supplements use among professional soccer players [2].

Due to the lack of data about supplements use among regular gymnasium users in Saudi Arabia, we conducted this study to try to understand the pattern of use among this population and to explore beliefs and intentions regarding supplements use. The Lebanese study was very comparable to our study and used similar methods. Our study found supplements use to be at $37.8 \%$ versus $36.3 \%$ in Lebanon. This might be due to similarity of age distribution of participants of the two studies, as most of our study population was between 22 and 33 versus 20 and 30 years old in the Lebanese study. Our findings showed that males form $89.4 \%$ and females $10.6 \%$ of the participants. In addition, sex difference between users and nonusers was statistically significant and users were more common among males. This finding concurs with the Lebanese study where males constituted $72 \%$ of supplements users while females amounted to $28 \%$. In Isfahan, Iran, males constituted $86.8 \%$ of study participants and females $11.2 \%$ $[9,11]$. This can be attributed to the fact that males were exercising more frequently than females. Both our population and the Lebanese showed that most of the subjects fall in the bachelors' degree educational status [9]. In contrast to the Lebanese study, we found a significant difference between the smoking status of supplements users and nonusers with smokers constituting $45.1 \%$ of users and $29 \%$ of nonusers [ 9 ].

Respondents consume a total of 25 supplements with the most common used supplements being whey protein $(22.1 \%)$, amino acids (16.8\%), multivitamins (16.8\%), creatine $(11.5 \%)$, and omega $3(11.5 \%)$ while the Lebanese study showed almost similar results with protein powder $(39.8 \%)$, amino acid pills $(34.9 \%)$, whey protein $(32.3 \%)$, creatine $(19.4 \%)$, and multivitamins (17.7\%) [9]. In comparison to male athletes in New York, the most common used supplement is multivitamin/minerals (45\%), followed by protein shakes/bars (42.3\%), vitamin C (34.7\%), and vitamin E (23.4\%) [7]. It is reported that some supplements that athletes use may cause some harm. For example, the amino acid has been shown to cause gastrointestinal adverse effects, mainly diarrhea and stomach cramps [15]. Creatine supplementation has shortand long-term side effects. The side effects of short-term use for 3 to 5 days include an increase in body weight 
TABLE 6: Beliefs about supplements use.

\begin{tabular}{|c|c|c|c|c|c|c|c|}
\hline $\begin{array}{l}\text { Belief about } \\
\text { supplements }\end{array}$ & Group & $n(\%)$ & Agree & Somewhat agree & Somewhat disagree & Disagree & Do not know \\
\hline \multirow{4}{*}{$\begin{array}{l}\text { Dietary supplements } \\
\text { make me healthier }\end{array}$} & \multirow{2}{*}{ Users } & $n$ & 46 & 39 & 1 & 26 & 1 \\
\hline & & $\%$ & 40.7 & 34.5 & 0.9 & 23 & 0.9 \\
\hline & \multirow{2}{*}{ Nonusers } & $n$ & 44 & 46 & 17 & 67 & 12 \\
\hline & & $\%$ & 23.7 & 24.7 & 9.1 & 36 & 6.5 \\
\hline$P$ value & & & & & & & \\
\hline \multirow{4}{*}{$\begin{array}{l}\text { Dietary supplements } \\
\text { are safe to use }\end{array}$} & \multirow{2}{*}{ Users } & $n$ & 41 & 41 & 6 & 20 & 5 \\
\hline & & $\%$ & 36.3 & 36.3 & 5.3 & 17.7 & 4.4 \\
\hline & \multirow{2}{*}{ Nonusers } & $n$ & 31 & 56 & 21 & 62 & 16 \\
\hline & & $\%$ & 16.7 & 30.1 & 11.3 & 33.3 & 8.6 \\
\hline$P$ value & & & & & & & \\
\hline \multirow{4}{*}{$\begin{array}{l}\text { Dietary supplements } \\
\text { increase the amount } \\
\text { of training I can } \\
\text { undergo }\end{array}$} & \multirow{2}{*}{ Users } & $n$ & 67 & 18 & 2 & 21 & 5 \\
\hline & & $\%$ & 59.3 & 15.9 & 1.8 & 18.6 & 4.4 \\
\hline & \multirow{2}{*}{ Nonusers } & $n$ & 78 & 40 & 17 & 35 & 16 \\
\hline & & $\%$ & 41.9 & 21.5 & 9.1 & 18.8 & 8.6 \\
\hline$P$ value & & & & & & & \\
\hline \multirow{4}{*}{$\begin{array}{l}\text { Dietary supplements } \\
\text { provide me with more } \\
\text { energy }\end{array}$} & \multirow{2}{*}{ Users } & $n$ & 51 & 24 & 6 & 27 & 5 \\
\hline & & $\%$ & 45.1 & 21.2 & 5.3 & 23.9 & 4.4 \\
\hline & \multirow{2}{*}{ Nonusers } & $n$ & 68 & 23.7 & 15 & 38 & 21 \\
\hline & & $\%$ & 36.6 & 15 & 8.1 & 20.4 & 11.3 \\
\hline$P$ value & & & & & & & \\
\hline \multirow{4}{*}{$\begin{array}{l}\text { Dietary supplements } \\
\text { increase my ability to } \\
\text { cope with pain }\end{array}$} & \multirow{2}{*}{ Users } & $n$ & 23 & 19 & 8 & 48 & 15 \\
\hline & & $\%$ & 20.4 & 16.8 & 7.1 & 42.5 & 13.3 \\
\hline & \multirow{2}{*}{ Nonusers } & $n$ & 30 & 22 & 21 & 58 & 55 \\
\hline & & $\%$ & 16.1 & 11.3 & 11.3 & 31.2 & 29.6 \\
\hline$P$ value & & & & & & & \\
\hline \multirow{4}{*}{$\begin{array}{l}\text { Dietary supplements } \\
\text { improve my } \\
\text { concentration }\end{array}$} & \multirow{2}{*}{ Users } & $n$ & 33 & 20 & 6 & 42 & 12 \\
\hline & & $\%$ & 29.2 & 17.7 & 5.3 & 37.2 & 10.6 \\
\hline & \multirow{2}{*}{ Nonusers } & $n$ & 28 & 33 & 16 & 60 & 49 \\
\hline & & $\%$ & 15.1 & 17.7 & 8.6 & 32.3 & 26.3 \\
\hline$P$ value & & & & & & & \\
\hline
\end{tabular}

$P$ value: $\chi^{2}$ test.

due to increase in total body water [16], and the longterm use of creatine ( 2 months) may result in limb edema in some trainers [17]. Despite these minimal side effects, the supplements mentioned above are legal to use by the International Olympic Committee (IOC) and the National Collegiate Athletic Association (NCAA) [18, 19]. No statistical difference between the frequency of exercise between users and nonusers was found in our study, a finding in agreement with the Lebanese study [9].

We found that most of the information pertaining to supplements use was obtained from unreliable sources such as online sources (38\%) and coaches (35.4\%). Physicians (13.3\%), academic journals (12.4\%), and dieticians (11.5\%) were less common as a source of information. The Lebanese study similarly reported coaches (44.6\%) and online sources (36.6\%) were the major source of information [9]. The study in Isfahan, Iran, reported coaches (65\%), nutritionists (30\%), and doctors $(25 \%)$ were the main sources of information to supplement users [11]. Saudi professional athletes reported that more reliable information sources were obtained from physicians (45.9\%) and dieticians (28.5\%) [2].

Furthermore, we investigated reasons for using supplements to understand why regular gymnasium users take them. Our subjects reported that the main reason is for better appearance $(47.7 \%)$, to improve health $(44.2 \%)$, and to improve performance $(41.5 \%)$. On the other hand, the main reasons for their use among professional athletes in Saudi Arabia were to improve performance (43.8\%) and to improve health (32.6\%) [2]. It is surprising that both professional athletes $(43.8 \%)$ and regular gymnasium users (41.5\%) respond similarly for using supplements to improve performance [2]. The New York study assessed the same 
issue and the results were comparable to ours. The most common reasons were building muscles (49.1\%), preventing future illness (38.4\%), increasing energy (36.1\%), improving performance in sports (24.4\%), gaining strength $(22.4 \%)$, and aiding in recuperation (20.5\%) [14].

Cardiovascular exercise was most common (49.6\%) among supplement users of our study participants. This is in contradiction to the Lebanese study where most supplement users (80.6\%) were engaged in strength training [9]. A statistically significant difference $(P<0.0001)$ in our study was found between supplement users and nonusers in terms of type of exercise practiced. Most supplement users were exercising for more than 1 year $(75.2 \%)$ and most nonusers exercised for less than 1 year $(61.8 \%)$, meaning that the more time spent exercising increases the likelihood of using supplements. Median BMI for supplements users was 24.8 and nonusers 27.6 , meaning that nonusers were significantly overweight in comparison with users $(P<0.0001)$. Diastolic blood pressure was significantly lower for users (72) compared with nonusers $(77)(P<0.0001)$ but it is still within the normal range. From the anthropometric measurements, we can deduce that users are in better physical shape than nonusers. This might be due to the longer period of exercise as most supplement users were exercising for more than 10 years and are more motivated. Although statistically significant, this might not necessarily conclude a strong correlation between the physical status and supplement use as it should be explored more on a larger sample of participants. No difference was found between supplement users and nonusers in relation to educational status, income, and sleeping pattern.

Our study is not without limitations, several of which should be acknowledged. We had difficulties in recruiting female participants. This resulted in most of our study participants being male. This is due to difficulty faced in getting approval by female gymnasia and this is due to cultural restrictions and not to disturb gymnasium users or break their confidentiality. We had some difficulties in identifying which supplements were common to be included in our questionnaire but we included a blank space to write which supplements the respondent was taking. Future studies should use sampling methods similar to other studies to make comparisons feasible. We recommend future studies to include a larger sample size with more female participants and use a standard data collection method.

In conclusion, supplement use among regular gymnasium users in Riyadh is common and more dominant among males. The main reasons for supplements use among our study participants were for better appearance and to improve health and performance. More studies are needed to have a more detailed depiction regarding supplements use among regular gymnasium users in Saudi Arabia. Health professionals including physicians and nutritionists need to be available in gymnasium centers to provide reliable information regarding supplements and their health hazards. In addition, awareness programs that explain the potential side effects of supplements and their interactions and reliable information sources should be made available.

\section{Conflicts of Interest}

The authors declare that there are no conflicts of interest regarding the publication of this paper.

\section{References}

[1] Central department of statistics and information, "Population (15 Years And Over) By Age Groups And Educational Status: $1434 \mathrm{H} / 2013 \mathrm{D}$," https://www.stats.gov.sa/en.

[2] S. O. Aljaloud and S. A. Ibrahim, "Use of dietary supplements among professional athletes in Saudi Arabia," Journal of Nutrition and Metabolism, vol. 2013, Article ID 245349, 7 pages, 2013.

[3] L. Burke, M. Cort, G. Cox et al., "Supplements and sports foods," in Clinical Sports Nutrition, pp. 485-579, McGraw-Hill, Sydney, Australia, 2006.

[4] M. S. Juhn, "Popular sports supplements and ergogenic aids," Sports Medicine, vol. 33, no. 12, pp. 921-939, 2003.

[5] C. Young, O. Oladipo, S. Frasier, R. Putko, S. Chronister, and M. Marovich, "Hemorrhagic stroke in young healthy male following use of sports supplement Jack3d," Military Medicine, vol. 177, no. 12, pp. 1450-1454, 2012.

[6] DSHEA, Dietary Supplement Health and Education Act of 1994. Pub L No103-417, 108 Stat 4325, 994, https://ods.od.nih.gov/ About/DSHEA_Wording.aspx.

[7] D. M. Jenkinson and A. J. Harbert, "Supplements and sports," American Family Physician, vol. 78, no. 9, pp. 1039-1046, 2008.

[8] O. Sánchez, M. Miranda, and E. Guerra-Hernández, "Prevalence of protein supplements use at gyms," Nutrición Hospitalaria, vol. 26, pp. 1168-1174, 2011.

[9] D. El Khoury and S. Antoine-Jonville, "Intake of nutritional supplements among people exercising in gyms in Beirut city," Journal of Nutrition and Metabolism, vol. 2012, Article ID 703490, 12 pages, 2012.

[10] B. J. Lyle, J. A. Mares-Perlman, B. E. K. Klein, R. Klein, and J. L. Greger, "Supplement users differ from nonusers in demographic, lifestyle, dietary and health characteristics," Journal of Nutrition, vol. 128, no. 12, pp. 2355-2362, 1998.

[11] J. Karimian and P. S. Esfahani, "Supplement consumption in body builder athletes," Journal of Research in Medical Sciences, vol. 16, no. 10, pp. 1347-1353, 2011.

[12] A. Heikkinen, A. Alaranta, I. Helenius, and T. Vasankari, "Dietary supplementation habits and perceptions of supplement use among elite Finnish athletes," International Journal of Sport Nutrition and Exercise Metabolism, vol. 21, no. 4, pp. 271279, 2011.

[13] K. Froiland, W. Koszewski, J. Hingst, and L. Kopecky, "Nutritional supplement use among college athletes and their sources of information," International Journal of Sport Nutrition and Exercise Metabolism, vol. 14, no. 1, pp. 104-120, 2004.

[14] L. J. Morrison, F. Gizis, and B. Shorter, "Prevalent use of dietary supplements among people who exercise at a commercial gym," International Journal of Sport Nutrition and Exercise Metabolism, vol. 14, no. 4, pp. 481-492, 2004.

[15] P. Clarkson, "Nutritional supplements for weight gain," Sports Science Exchange, vol. 11, article 68, 1998.

[16] T. Ziegenfuss, L. Lowery, and P. Lemon, "Acute fluid volume changes in men during three days of creatine supplementation," Journal of Exercise Physiology, vol. 1, no. 3, 1998.

[17] G. J. Groeneveld, C. Beijer, J. H. Veldink, S. Kalmijn, J. H. J. Wokke, and L. H. Van Den Berg, "Few adverse effects of longterm creatine supplementation in a placebo-controlled trial," 
International Journal of Sports Medicine, vol. 26, no. 4, pp. 307313, 2005.

[18] World Anti-Doping Agency, Prohibited List, WADA, Montreal, Canada, 2015, https://www.wada-ama.org/en/what-we-do/prohibited-list.

[19] 2016-17 NCAA Banned Drugs List, September 2016, http://www .ncaa.org/2016-17-ncaa-banned-drugs-list. 


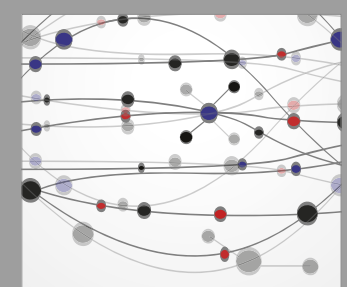

The Scientific World Journal
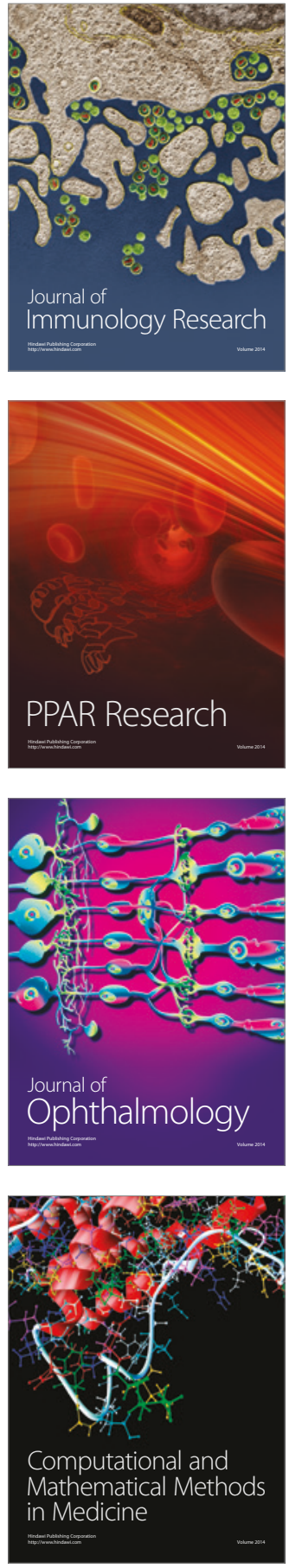

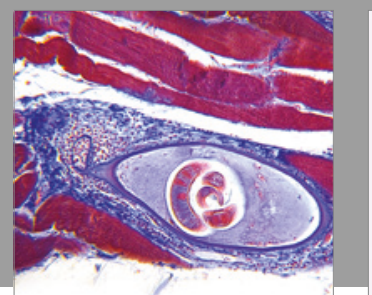

Gastroenterology Research and Practice
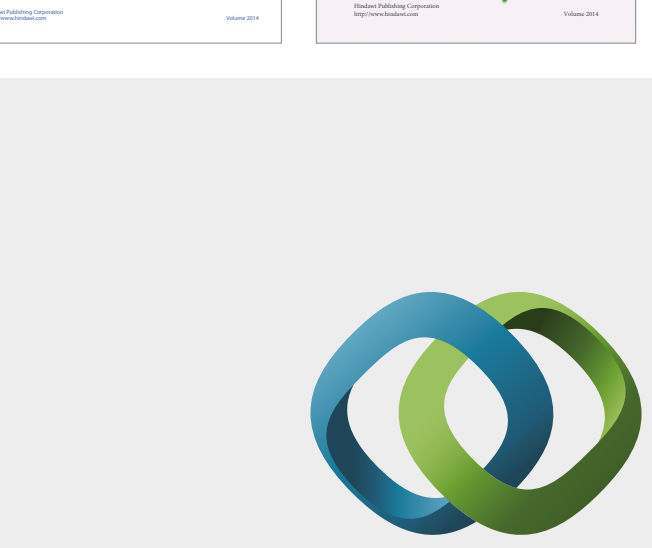

\section{Hindawi}

Submit your manuscripts at

https://www.hindawi.com
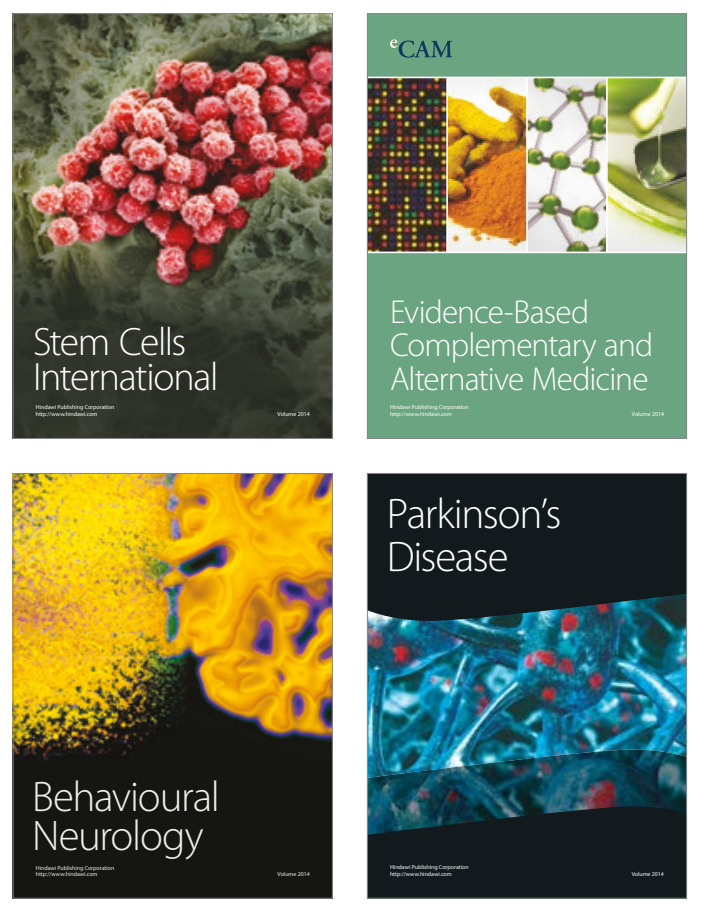
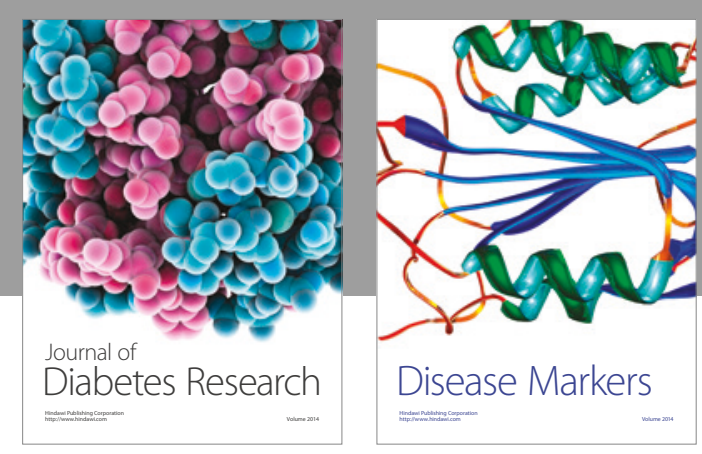

Disease Markers
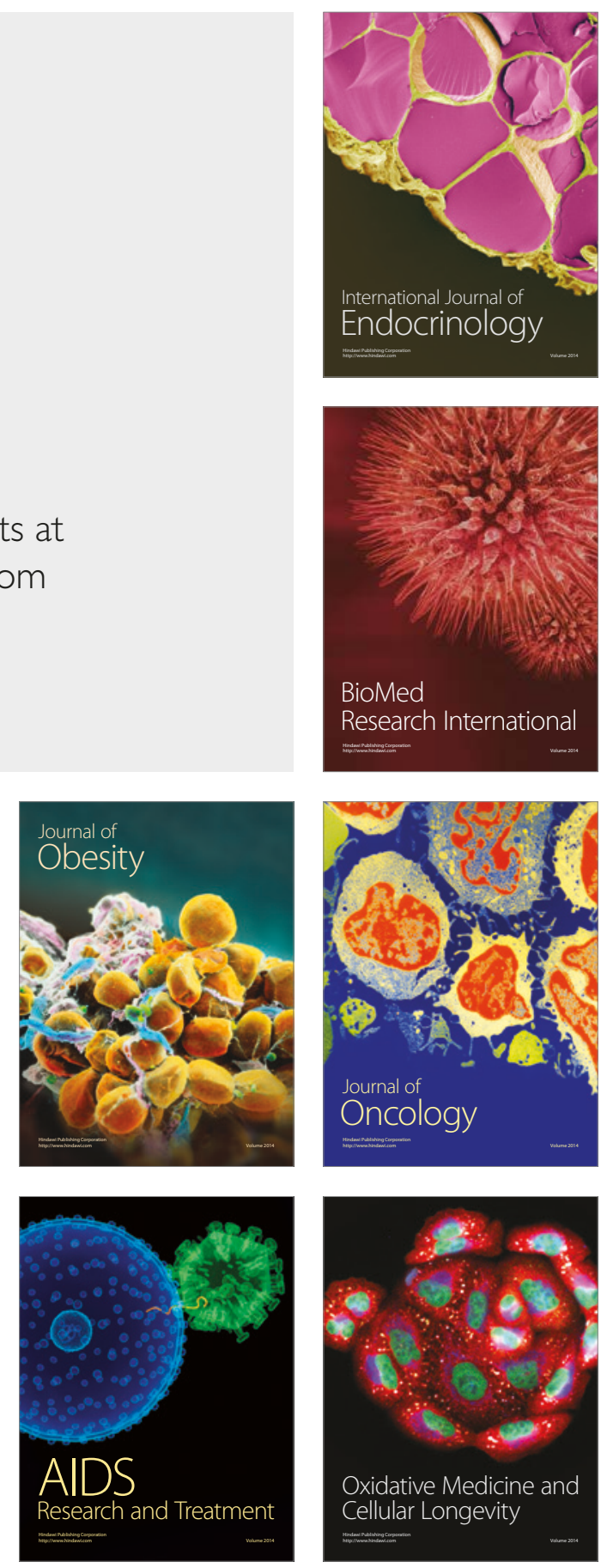